\title{
FRIENDLY COMBAT OVER MORAL COMBAT: A REPLY TO MY CRITICS*
}

\section{UN COMBATE AMISTOSO SOBRE COMBATE MORAL: RESPUESTA A MIS CRÍTICOS}

\author{
Heidi M. HuRD**
}

\begin{abstract}
Resumen:
En esta pieza respondo a los críticos que sostienen que el combate moral no sólo es posible, sino ubicuo. En opinión de algunos, la moralidad está relacionada con los roles, y por lo tanto el paquete único de razones para la acción que posee alguien dentro de un rol determinado puede dictar un curso de conducta que frustre las acciones requeridas de otros que no comparten ese rol. Otros críticos defienden, en cambio, el relativismo moral meta ético, del que se deduce que dos personas que provienen de culturas distintas pueden tener razón (en relación con sus "formas de vida" separadas) al frustrar las acciones del otro. Una tercera línea de ataque es la de los críticos que creen que ciertos valores morales de primer orden son inconmensurables, y que, por lo tanto, sostienen que dos personas pueden ser inocentes al perseguir objetivos inconmensurables, pero mutuamente incompatibles a expensas del otro. Como sostengo, estas tres estrategias no logran reivindicar la afir-

${ }^{*}$ Artículo recibido el 20 de julio de 2019 y aceptado para su publicación el 25 de septiembre de 2019.

${ }^{* *}$ Ross and Helen Workman Chair in Law, Professor of Philosophy, and Co-Director of the Illinois Program in Law and Philosophy, University of Illinois, 504 E. Pennsylvania Avenue, Champaign, IL, 61820; hhurd@illinois.edu. I am very grateful to my colleagues in the Brazilian academy whose contributions to this collection probed the durability of my work on the topic of moral combat. I am particularly indebted to Thomas Bustamante for generously hosting a gathering at the Federal University of Minas Gerais in honor of the twentieth anniversary of my book, Moral Combat, which allowed for lively discussion of the challenges pressed by the contributors to this collection. It was by virtue of his energy and ambition that I am honored by the publication of their insightful critiques, and by the ability to respond to them in this short Reply.
\end{abstract}

Problema. Anuario de Filosofía y Teoría del Derecho, núm. 14, enero-diciembre de 2020, pp. 147-172 Ciudad de México, ISSN 2007-4387, se distribuye bajo una Licencia Creative Commons Reconocimiento-No Comercial-Sin Derivados 4.0 Internacional (CC BY-NC-ND 4.0). 
HEIDI M. HURD

mación de que nuestra mejor teoría de la moralidad tolera los encuentros de gladiadores en los que el éxito moral de una persona requiere el fracaso moral de otra.

\section{Palabras clave:}

Combate moral; razones relacionadas con el rol; relativismo; perspectivalismo; tesis de la correspondencia; inconmensurabilidad.

\section{Abstract:}

In this piece, I respond to critics who maintain that moral combat is not only possible, but ubiquitous. In the view of some, morality is role-relative, and thus the unique package of reasons for action possessed by someone within a given role may dictate a course of conduct that thwarts the actions required of others who do not share that role. Other critics instead defend meta-ethical moral relativism, from which it follows that two people who hail from distinct cultures may both be right (relative to their separate "forms of life") in thwarting the actions of the other. A third line of attack is mounted by critics who believe that certain first-order moral values are incommensurable and who thus argue that two people may both be blameless in pursuing incommensurably valuable but mutually incompatible goals at each other's expense. As I argue, all three of these strategies fail to vindicate the claim that our best theory of morality tolerates gladiatorial encounters in which one person's moral success necessitates another's moral failure.

Keywords:

Moral Combat; Role-Relative Reasons; Relativism; Perspectivalism; Correspondence Thesis; Incommensurability. 
It is both gratifying and humbling to be invited to respond to the provocative challenges to my past work that have been posed in this volume by scholars of distinction and stature whose own work merits similar compliments. While those outside the academy are understandably baffled by the notion that criticism can be a form of flattery, those of us who labor in the fields of ideas well appreciate that intellectual disagreement is the fuel that powers the tractors of truth, and that when others invest time and energy in critiquing one's work, it is proof that that work has been useful, if only because it has inspired them and others to do better. I am thus honored by the willingness of Vinicius Faggion, Ronaldo Macedo, Saulo Matos, Thomas Bustamante and Thiago Decat to inquire into the staying power of my twenty-year old work on moral combat, ${ }^{1}$ and I am delighted by the ways in which their vigorous critiques reveal previously undiscovered puzzles and paradoxes that provide invaluable fodder for future work.

My own current thinking about moral combat is explored in this volume in a new article co-authored with Michael Moore. ${ }^{2}$ Inasmuch as that piece re-articulates and freshly motivates my view that our best moral theory would not give actors either rights or duties to perform actions that are mutually thwarting, I shall not dedicate any time here to reminding readers of that view. Instead, I shall devote this short contribution to responding to some of the main theses within the critiques that my intellectual comrades have offered in this symposium. Each of their contributions is rich in arguments and implications, and I will undoubtedly fail to do justice to many of their important insights and challenges. But I shall try to identify and engage their most significant themes so as to make vivid the important counter-positions that they stake out counter-positions that will undoubtedly prove tempting to others who are vexed by the relationships between the rights, duties, and permissions that determine the scope and limits of our morally relevant choices.

1 Heidi M. Hurd, Moral Combat (Cambridge University Press 1999).

2 Michael S. Moore and Heidi M. Hurd, "Moral Combat: Disagreement in Action, Not Belief" in this volume, pp. 7-55. 
Let me begin by recognizing the happy coincidence of Vinicius Faggion's views with my own. In his thoughtful contribution, Faggion joins me in rejecting the view that morality is role-relative. ${ }^{3}$ In his words, roles are not morally "generative"; that is, they do not usher in rights, duties, or permissions that are unique to those who occupy them. As a result, the reasons for action that bear on the rightness of the decisions made by actors who occupy different roles cannot simultaneously make actions that prevent or thwart one another right. In other words, one cannot ground the possibility of moral combat in the role-relativity of reasons for action.

Faggion usefully distinguishes two versions of the generative thesis before advancing reasons to reject them both. On the "strong" view, a role is defined by unique rights, duties, and permissions that exhaust the criteria for right action within that role. Roles are, on this view, fully "insulated realms of moral valuation". ${ }^{4}$ Thus, rights, duties, and permissions that would apply to the actor outside of a role play no part in determining the rightness of her actions within a role. There may, of course, be numerous substantive duplications between an actor's role-relative duties and those that apply outside of that role, but in the event of a conflict between an all-things-considered judgment about an actor's role-relative reasons for action and an all-things-considered judgment about the actor's non-rolerelative reasons for action, the actor is bound to act in accordance with the dictates of her role. Thus, if the role of a judge demands the exceptionless application of the plain meaning of the law (when such a plain meaning is present), it is impermissible for a judge to issue a judgment that flies in the face of the law's plain demands. In a jurisdiction that conditions self-defense on the immanency of peril, a judge would violate not only the law but morality itself if the judge acquitted an abused wife who killed her husband in his sleep for fear that when he awoke to make her peril immanent, she would be unable to muster the force necessary to defend herself.

3 Vinicius de Souza Faggion, "Is the Judicial Role Just a Descriptive Social Fact?", this volume, nota 3: pp. 57-78.

4 Faggion, p. 70. 
In contrast to the strong view, Faggion articulates a weaker view that softens the degree to which actors within roles are precluded from accessing the reasons for action that would otherwise determine the rightness of their decisions. On this view, those who occupy roles are entitled to reach to reasons for action that cohere with the "ends" that justify their roles to begin with. Thus, for example, if the end that justifies having judges as means is the achievement of individualized justice, and if such an end can be achieved only by acquitting battered wives whose preemptive killings were reasonably believed to be necessary for self-preservation, then "judges who nullify the law are not acting lawlessly because the role itself permits this kind of incorporation of ordinary morality". 5 As this example makes clear, this weaker view permits "outside" moral considerations to enter into the reasoning of those within given roles when the rationale for those roles permits such outside appeals. Or, as Faggion puts it, "the role grants permission for the agent to think from an all-things-considered valuative domain". ${ }^{6}$ Just as some believe that laws should be interpreted so as to conform to their spirit rather than their letter whenever the two conflict, so on this view, roles should be executed in accordance with their spirit. As such, those who occupy such roles may, from time to time, offend against role-relative expectations when so doing allows them to honor the rationales for their having such roles to begin with.

Let me take Faggion's thoughtful complaints with these two "generative" theories in reverse order, because I find his critique of the weak view of role-relative constraints to be fully convincing, and thus easily endorsed. In Faggion's view, there are two reasons to think that the weak view is internally contradictory, or in some similar manner self-defeating. Drawing inspiration from the critique advanced by Anthony Reeves, ${ }^{7}$ Faggion first argues that in order to specify the domain of a role - in order to determine the highest

5 Faggion, p. 65 (quoting W. Wendel, “Three Concepts of Roles” 552 Cornell Law Faculty Publications (2011)).

6 Faggion, p. 65.

7 Anthony R. Reeves, "Do Judges Have an Obligation to Enforce the Law?: Moral Responsibility and Judicial-Reasoning" (2010) 29 Law and Philosophy 159-87. 
and best goal it serves- we must invoke "an all-things-considered moral point of view". When conventional understandings of the role conflict with the value that is assigned to that role through such an holistic exercise in moral reasoning, they are not deemed to be genuine aspects of the role, and as such, the occupant of the role is free to reach a judgment that appears (but only appears) to reach beyond the role. But if this is the case, the role itself is doing no work to generate reasons for action; all the work is being done by the value that is served by the role - a value that is not, itself, role-relative.

By way of a second route to the same judgment about the indefensibility of the weak theory of role-relative morality, Faggion appears to adopt an argument that is reminiscent of the famous arguments leveled at two-tiered theories that assign to systems goals distinctly at odds with the goals assigned to the individuals who are charged with their operation. Recall, for example, John Rawls' argument that a system of criminal justice must be justified on utilitarian grounds, but adjudicators within that system should be thought bound to honor the retributivist's goal of according punishment if, but only if, it is deserved. ${ }^{8}$ As David Lyons argued in his chestnut rebuttal, there can be no principled means of walling off the rationale for a system from the rationale for its case-by-case administration. ${ }^{9}$ If the reason to have a system of punishment is to advance utility summed across all, then what would justify a judge in refusing to administer a punishment (or grant an acquittal) that would plainly do just that (all utiles considered), even if it would be at odds with the defendant's just deserts? Similarly, as Faggion asks, what could justify a judge in confining herself to the role-relative reasons for a decision that are dictated by the value that is generally served by her so doing, when those reasons dictate a result that, in the case before the judge, violates that value?

I find both of these accounts of why the weak theory is unsustainable to be convincing. As I would put the problem, "there is no there

8 John Rawls, "Two Concepts of Rules" (1955) 64 The Philosophical Review 3-32.

9 David Lyons, Forms and Limits of Utilitarianism (Oxford 1965). See also Larry Alexander, "Pursuing the Good-Indirectly" (1985) 95 Ethics 315-332 (for a similarly powerful take-down of the defensibility of rule-utilitarianism). 
there" for such a theory. If every time that the judicial role dictates a result that is at odds with morality a judge is entitled - by the judicial role itself - to substitute the demands of morality for the apparently immoral demands of the law, then the judicial role never pinches at all, for it plainly does not compel action in accordance with a set of reasons that apply only to those within the role. This does not mean that the judicial role is simply a "descriptive social fact" as Faggion concludes. On the contrary, this makes the judicial role a morally-weighty one, for all of morality then necessarily informs, and dictates the legitimacy of, judicial decisions. The judicial role cannot exclude some considerations as irrelevant while adding morally-artificial weight to others.

Let me now turn to Faggion's criticism of the strong view. As a careful reading reveals, Faggion's principal argumentative strategy is to reject the moral relativism that he assigns to those who embrace that view — which is, as he puts it, a bullet too bitter to bite. ${ }^{10}$ While I have no truck with moral relativists, ${ }^{11}$ my fear is that Faggion converts those who hold the strong view into straw men by equating their version of role-relative morality with moral relativism. It is true, but only trivially so, that those who subscribe to moral relativism can make sense of why those in different roles might have different reasons for action. And it is true, but only trivially so, that this explanation vindicates the possibility of moral combat. If actions are made right by the beliefs of those who perform them (as subjectivists maintain), or if actions are made right by the shared beliefs (i. e., conventions) of communities (as conventionalists maintain), then it is unsurprising that one actor might be right in performing an action that prevents the right action of another and vice versa, for it is unsurprising that these actors may hold conflicting beliefs or be members of distinctly different communities whose conventions conflict. The possibility of moral combat inexorably follows from moral relativism, so if those who hold the strong view concerning the rolerelativity of morality do so because they are moral relativists, then

\footnotetext{
10 See Faggion, p. 69.

11 Heidi M. Hurd, "Relativistic Jurisprudence: Skepticism Founded on Confusion" (1988) 61 Southern California Law Review 501-593.
} 
it is true, but tautological, that they may think of moral combat as ubiquitous.

The strong view of role-relative morality that Faggion identifies becomes much more interesting, and much more formidable, if it does not trade on meta-ethical moral relativism. If, instead, we make the strong view the strongest it can be by giving it realist underpinnings, then the position constitutes a view of morality that nontrivially implies the possibility — indeed, the probability- of moral combat. On this view, roles reflect packages of moral reasons for action that are exhaustive of the reasons for action possessed by those within such roles, because morality (conceived of as a source of truths that are belief-and-convention-independent) is simply constituted by such autonomous packages. One actor's role-relative package of reasons might dictate action $A$, while another actor's role-relative package of reasons might dictate action $B$, where actions $A$ and $B$ each prevent or thwart the successful completion of the other. As such, each actor's moral success will turn on the other's moral failure, so in such a circumstance actors are locked in moral combat, for the one cannot do right without the other doing wrong.

This is the thesis about which I took myself to be providing a book-length critique in Moral Combat, and it is the thesis that Michael Moore and I further pursue in our contribution to this symposium when demonstrating both that Wesley Hohfeld's famous deontic logic permits moral combat, and that this is so much the worse for his iconic system. We are glad to claim Faggion as an ally, but it is crucial to recognize that more is needed to defeat the strong view about role-relative morality than a convincing critique of moral relativism.

I am, however, happy for the muscle that Faggion's critique of relativism brings to the fight that Ronaldo Porto Macedo Jr. and Saulo M.M. Matos pick with my work - a fight that makes the defensibility or indefensibility of moral relativism the trophy. While substantially different in their very interesting and thoughtful details, Macedo's and Matos's contributions press the view that I am not entitled to the particular brand of moral realism that implicitly un- 
dergirds the problem of moral combat to which my work is devoted. In their view, there are meta-ethical theories that locate themselves between sophomorically simple versions of moral relativism and robust versions of moral realism that are not only defensible, but attractive. And therefore, the problem of moral combat is not a problem of significant moral interest. Moral combat may remain -indeed, it may be ubiquitous - because people who enjoy different "forms of life" may find themselves in circumstances in which the moral tenets of their separate social practices conflict so as to demand that one perform an action that is the undoing of another's. But this follows somewhat trivially from the fact that, as Macedo insists, people may hail from diverse cultures that each demand actions inconsistent with those demanded by all others. While the precepts of those different cultures "do not straightforwardly contradict one another ...they do exclude one another". ${ }^{12}$ They reflect Wittgensteinian "forms of life" that despite shared "family resemblances", comprise social practices that help their members "find [their] way around" in "many different cultures in which they can live, differing in their local concepts". ${ }^{13}$ Quoting Bernard Williams, Macedo writes: "The use of ethical language... depends on a shared form of life and the practices of a community within which we pick up the terms of our ethical experience". ${ }^{14}$ As such, it should not be surprising if morality makes an action in one such community right that would be wrong if done in another. And it should not be surprising that an actor who is obligated by the social practices of her community may be obligated do an act that prevents or thwarts the action of another who is obligated by the quite different social practices of his community.

While Matos agrees that moral facts are dependent on "sharing a form of life" and are a function of participating with others in a dis-

12 Ronaldo Porto Macedo Jr., “Is Bernard Williams' Distance Relativism Really Defeated by Heidi Hurd's Attack on Perspectivalism?”, this volume, pp. 96-97.

13 Macedo, p. 90.

14 Macedo, p. 95 (quoting Bernard Williams, "The Need to Be Skeptical" in Essays and Reviews: 1959-2002 (Princeton: Princeton University Press 2016), p. 314 . 
tinctive "argumentative practice", ${ }^{15}$ his path to the same conclusion about morality's tolerance of moral combat follows a different route. In his view, moral tenets lean on social practices that are not themselves fully specified. As such, our moral obligations are "underdetermined", and thus, "the task of law consists above all in offering institutional schemes of cooperation so that moral values can be followed and determined in the context of social practices". ${ }^{16}$ The law, on this approach, never departs from morality, for the law is constitutive of what persons must do within a social system in which law is the recognized source of salient solutions to coordination problems that all must overcome for their own sakes and others'. On Matos's view, within a community that shares "a form of life" that is coordinated by laws, no one is ever justified in breaking the law, so the prospect of moral combat between citizens who are right to break the law and judges who are right to enforce it against them never arises. Of course, inasmuch as there are multiple "forms of life", each of which can have significantly different strategies for resolving coordination problems, there is ample room for moral combat between those who meet in the moral equivalent of the demilitarized zone between their two social worlds. But this is practically a tautological consequence of construing morality as function of shared social practices and legal institutions in a world in which there are multiple versions of such "forms of life".

Macedo and Matos both agree that a Wittgensteinian approach to ethics preserves a kind of objectivity about ethics, because the truthvalue of moral propositions is not thought to be relative to shared social practices on such a view. Rather, moral tenets are thought to be intimately responsive to social practices, and ultimately partially constitutive of those practices. Ethical propositions thus share the same (sociological) objectivity of the cultures from which they arise and to which they lend constitutive support. In Macedo's and Matos's view, the truth of moral propositions is not itself relative to the beliefs of individuals or the conventions of a community. But inas-

15 Saulo M.M. de Matos, "A Wittgensteinian-Based Moral Realism: Deflating Hurd's Moral Combat Antimony", this volume, pp. 121-122.

16 Matos, p. 122. 
much as the point of moral propositions (and legal ones that specify them further) is to guide action within distinct social environments, the content of moral propositions may vary considerably between significantly different social environments - so much so that it would be unsurprising if they proved contradictory when subjected to pair-wise comparisons, or did not at least imply that those within such distinct social environments would face moral combat were they ever to breach their cultural barriers.

Macedo and Matos are not wrong to believe that I subscribe to metaethical moral realism - that is, to the dual-pronged ontological thesis that moral truths exist and are conceptually, if not substantively, independent of any individual's or group's beliefs about them. But I do not take my book-length treatment of the possibility and implications of moral combat to depend on a defense of robust metaethical moral realism, and this is why I did not provide one. Instead, I take moral combat to follow from any view that takes the truth of moral propositions (of a first-order, second-order, or even third-order stripe) to be relative to the beliefs that individuals or groups may hold. It is this form of relativism that makes it trivially possible, on conceptual grounds, for two people (perhaps of two different cultures) to be morally successful only if they prevent or thwart the actions of one another. If Macedo and Matos succeed in finding in the later work of Wittgenstein, or in some better reading of Bernard Williams, some "there there" between traditional versions of relativism and robust forms of realism, perhaps they will be able to articulate a view of morality that is both objective and that makes it objectively true - but not tautologically so- that morality may demand actions of us that entail moral combat.

This is not the place to repeat or try to improve upon the detailed arguments I have made in Moral Combat and elsewhere that cast shade on the likely success of this search for metaethical middle ground. Instead, let me make a set of peace offerings to Macedo and Matos; that is, let me make a significant set of concessions to their thoughtfully-crafted contributions that are designed to close the ground between us. As they will recognize, these concessions do not add up to an admission of defeat; on the contrary, they are designed 
to demonstrate how realism is fully consistent with a number of the considerations that motivate them to seek an alternative that feints in the direction of relativism. Still, there is much in what both of them say that merits agreement, and to the extent that my previous work did not make this clear, Macedo and Matos are to be thanked for allowing me to demonstrate the compatibility of my realism with tenets of their particular anti-realist theories.

First, there is no question that the conventions that characterize cultures and guide our social interactions merit epistemic deference. Just as two heads are better than one when it comes to figuring out a problem, so the lessons that have been learned over long time-spans by groups of people facing shared challenges are likely to be helpful heuristics when assessing what is required of them as a matter of morality. While, in my view, individuals, groups, and entire societies can be wrong about the content of morality - wrong about the precepts that define right action and the rules to which they therefore ought to adhere- any good realist can harbor the optimism and hazard the guess that, over time, truth will cause belief (just as it does in science), and therefore, the "forms of life" that evolve to define distinct cultures within distinct environments are appropriately thought to be evidential of what morality requires of their members in those circumstances.

To admit this, of course, goes no distance toward admitting that the variation between social and cultural "forms of life" vindicates the existence of actual moral combat; it simply makes sense of why moral combat appears possible. As I make clear in my book, the correspondence thesis - which holds that the justification of one person's action determines the justifiability of permitting or preventing that act - is patently false if construed as an epistemic theory about the conditions of culpability. Two individuals can each justifiably believe that they are entitled to thwart the actions of the other, because they can each possess different information concerning what they are entitled to do; and this is very likely to be the case when they hail from cultures or social settings characterized by norms and rules alien to one another, so as to reach to radically different heuristics as evidence of how they ought to interact. 
Second, not only will cultural conventions and social rules invite justified epistemic deference in ways that may pit agents against one another in apparent moral combat, but cultural conventions and social practices can also be context-sensitive applications of more general moral maxims so as to be not just epistemically justified, but objectively true propositions about right action. In a world in which there are no palliative measures by which to deal with the acute pain of loved ones, the maxim that we owe special duties of care to those who are near and dear may properly translate into a license to aid in their suicide, or even engage in active euthanasia. In a world in which acute pain can be managed with the help of modern pharmaceuticals and palliative practices, anyone who would rush to euthanize a loved one would be a moral monster, not a moral hero. The point: a general moral maxim that is equally true in two very different cultures may justify radically different, and even diametrically opposed practices. This is not an embarrassment to moral realism. It is simply the recognition that moral maxims are context-sensitive. If what is possible in one world is not possible in another, then inasmuch as ought implies can, what one may be morally obligated to do in one world may be quite different than what one is morally obligated to do in the other.

Once again, the fact that any sensible moral realist must recognize the context-sensitivity of moral maxims goes no distance toward conceding that moral combat is conceptually baked into our best moral theory or is an inherent feature of our daily lives. That our shared social circumstances embody solutions to moral problems that are a product of the constraints of our past and present circumstances does not suggest that two people, in a given context, would be right to thwart one another's actions. Were I to find myself in a world in which the only escape from acute pain is death, I would not be entitled to thwart another's effort to deliver that relief to a loved one who sought it; and were she to find herself in my world in which pain can be dulled through drugs, she would not be entitled to thwart my palliative care through measures that would bring relief only by bringing death. That morality is context-sensitive and thus realized within different contexts in ways that may appear contra- 
dictory or conflicted, does not mean that in a given context it permits moral combat.

Third, Matos is absolutely right in insisting that "democratic processes can change the moral profile of what is demanded in a society" and this "can be considered a strong reason for a person to comply with the laws of the political community, insofar as the mere existence of such institutional arrangements already puts such a community in a better moral situation than that offered by the uncertain or underdetermined normative content of morality". ${ }^{17}$ While Matos explicitly argues for only one sense in which this claim is true (as a way of defeating my view that it is sometimes morally permissible, and even obligatory, to break the law), I want to tease out four distinct ways in which social and legal practices can indeed be rightmaking.

First, as Matos maintains, "institutional practices... have the function of providing arrangements or schemes for cooperation among citizens". ${ }^{18}$ Coordination problems arise when members of a group share an interest in coordinating their conduct but lack a salient means of choosing from a set of equally possible and equally morally eligible options a single course of conduct that will unite their efforts. As John Finnis points out, coordination problems arise not only when coordination is advantageous, but also when it is obligatory. For example, inasmuch as we are obligated not to harm others, we are obligated to seek means of coordinating our fast-moving travel to avoid accidental collisions. There is no ex ante right answer as to how such coordination ought to be achieved, and thus any solution that emerges as salient has right-making properties. Once we can reasonably predict that others will conform their behavior to a solution that is emerging as salient, morality requires us to follow suit so that we can secure for ourselves and others the benefits that flow from coordination. Thus when social norms, practices, and conventions function as salient solutions to coordination problems, they make actions right that would have been wrong had contrary salient solutions emerged, and that were neither right nor wrong

17 Matos, p. 118.

18 Matos, p. 117. 
prior to the emergence of any such solutions. The same is true, as Matos argues, with regard to laws that derive their value from their ability to provide salient solutions to coordination problems. Even if laws do not encapsulate the solutions that we wish had emerged when a solution was sought, the fact that they are "second best" in a world in which "first best" is no longer feasible gives ample moral ground to abide by their terms. ${ }^{19}$

To admit this again gives no ground to those who take morality to be perspectival in some deeper sense. There are lots of "moral ties" in life - lots of instances in which morality is under-determinative because two or more means of coordination are equally welfare-enhancing, or because two or more means of coordination are consistent with the duties, rights and permissions that individuals possess. The point is that once one can predict that others will settle the indeterminacy in favor of a given coordination solution, that solution becomes morally weighted by the goods that follow from achieving coordination and by the independently significant value of honoring others' expectation and reliance interests. There remains no prospect of moral combat, for each person's moral success turns on being collaborative with others, not combative. When people meet in the interstices of two systems that embody conflicting means of resolving coordination problems, they may be without a means of coordination, for they can predict that neither of the two solutions salient in their systems are salient in their overlapping penumbras. But this would not entail that they face moral combat. On the contrary, because their moral success turns on avoiding conflict, they will act rightly only if they reason iteratively to a win-win solution that is salient for both.

The second sense in which social practices, rules, conventions, and laws can be genuinely right-making is that they can helpfully convert "imperfect duties" into "perfect" ones in ways that reduce both the ontological and epistemic indeterminacy of what morality requires of us. "Imperfect duties", like the duty of charity, per-

19 "Even if ...a [tax] scheme ends up not being fair, there is a moral obligation from all citizens to comply with tax laws, since without them the moral situation of society is worse, given the lack of a cooperation scheme". Matos, p. 117. 
mit substantial discretion concerning the terms of their fulfillment. To satisfy one's duty of charity, one need not give away all one has, and one need not give to all in need. As Matos observes, "there is a moral obligation to help the needy, but at the same time there are considerable doubts about what is the best mechanism to offer such help". ${ }^{20}$ If tax law takes from each of us what we imperfectly owe to others as charity, and if it ensures that it reaches those in greatest need, then the availability of a tax system may convert my imperfect duty of charity into an annual perfect duty to pay taxes if the government then redistributes my dollars to unknown and unknowable citizens whose need for it grounds my duty to give a portion of my wealth away to begin with.

Yet again, it is clear that this concession does not lend support to the conclusion that morality might make room for the possibility of moral combat - that it might allow two people to be equally right in their beliefs that what they must do comes at a cost to the other's moral success. Precisely because imperfect duties are discretionary in their demands concerning when, where, and toward whom they are owed, they cannot require of one person an action that entails that another's morally required action must be prevented. Indeed, one might think that the virtue of recognizing that many moral duties are imperfect, rather than perfect, is that one can breathe easier about the unhappy prospect of finding oneself at risk of moral combat, for one would not be entitled to fulfill an imperfect duty in a given time and place if it confounded another's ability to satisfy a perfect duty, or even an imperfect one that could not otherwise be fulfilled. And if legal institutions such as tax law (and, as I argue elsewhere, bankruptcy law ${ }^{21}$ ) are able to convert imperfect duties into perfect ones, then so much the better for them. Inasmuch as I do not take laws to trump moral judgments in instances of conflict, and inasmuch as Matos has not given any rea-

20 Matos, p. 117.

21 Heidi M. Hurd, "The Virtue of Consumer Bankruptcy" in R Brubaker, RM Lawless, CJ Tabb (eds.), A Debtor World: Interdisciplinary Perspectives on Debt (Oxford 2012) 317-344; Heidi M. Hurd and Ralph Brubaker, The Virtue of Bankruptcy (Oxford, forthcoming). 
son to think otherwise (since his arguments are designed, instead, to suggest that there are never such conflicts), I am not worried that the perfect duties that are generated will ever make justified the punishment of those who justifiably violate them.

The third sense in which Matos is right to emphasize the rightmaking capacity of democracy follows from recognizing the plausibility of thinking that individuals can have agent-relative reasons for action that can make right for them actions that would not be right for others who lack those reasons. To recognize such agent-relative reasons for action is not, however, to say that morality is perspectival or that roles analogously give distinct reasons for action. Let me explain. As Thomas Nagel famously argued, if one wants to climb a mountain -if one takes it to be one of the projects that defines how one's life should go- one has a reason to climb the mountain. It is, of course, a defeasible reason; it can be outweighed by many other reasons that speak in favor of giving one's spare time over to other projects or to the satisfaction of obligations owed to others. But absent other overriding reasons, it may be sufficient to make the climbing of that mountain the right thing to do. Someone else who does not share this ambition, on the other hand, lacks a reason to climb the mountain. Her own projects, in turn, will give her agentrelative reasons to do alternative things with her spare time that may, by themselves, make her pursuit of any one of those projects the right thing to do at any given time.

If individuals plausibly have agent-relative reasons to pursue their own projects in the absence of other overriding personal duties, then it is a small step to the conclusion that groups of individuals can plausibly have shared agent-relative reasons to give themselves laws that constrain their individual liberties in ways that will achieve collective goods. Once institutionalized, these laws may retain their right-making power if the collective goods they guarantee do not infringe the rights of others, even if those laws do not turn out to be the laws that the citizenry would pass again if they could rewrite history. We take it to be moral to live by democraticallycommitted mistakes of the past because the collective arrangements those decisions made possible continue to bear fruit, and because 
reversing those laws would be more costly than beneficial, given the rule of law values that would be unsettled by radical revisions that would thwart reliance interests, chill liberty, and perpetrate inequalities. And thus, democratically-enacted laws can indeed be all citizens need in order to determine how they ought to act, not because those laws possess practical authority, but because compliance with them will constitute the best a citizen can do, as a moral matter, given the moral weight to be assigned to the law's original democratic pedigree and to the values that are served by continuing to honor the law's demands even after it has proven to be a secondbest strategy in world in which a first-best strategy is no longer possible.

This concession and those that came before go a long way toward granting Matos and Macedo their central claim that laws and the social practices they embody and make determinate can make right actions that would otherwise be wrong, or permit the moral evaluation of actions that would otherwise be amoral. But as I have argued, none of these concessions admit that what is moral is relative to people's beliefs about whether it is moral, for I take all of these concessions to be true whether people believe them or not. And none of these concessions suggest that legal obligations and moral obligations can never conflict (even if some legal obligations do perfectly embody some moral obligations because they solve coordination solutions or convert imperfect to perfect obligations). And therefore none of these concessions eliminate the possibility that citizens might be right to violate laws while judges might be right to punish them for so doing; or that system designers might be right to punish judges for justifiably exonerating citizens who are themselves justifiably civilly disobedient. Finally, none of these concessions amount to cornerstones of the philosophical monument to Wittgenstein that Macedo and Matos take themselves to be erecting. They are, instead, fully compatible with a robust form of moral realism that rejects the notion that morality is simply a helpful construct for people who are in need of navigational heuristics that will rescue them from disapprobation and guard them against unpleasant sanctions as they engage with others in complex social 
practices that are constitutive of their distinct cultures and societies. And thus, none of these concessions make the possibility of moral combat either impossible or trivially common as to make my past concerns about its scope and implications misguided.

Yet a powerful rejoinder remains that, if true, threatens to force such a surrender. If, morality assigns incommensurable values to a variety of goods, as Thomas Bustamante and Thiago Decat argue in their challenging contribution, ${ }^{22}$ then this seemingly makes moral combat at least logically possible, because it gives rise to the prospect that two agents might blamelessly thwart one another when pursuing mutually inconsistent projects of incommensurable value. Autonomy is valuable, according to Bustamante and Decat, because it enables one to choose which options among many to pursue when all are incommensurably valuable - when none can be thought more or less valuable than others and when none can be thought to be of equal valuable, precisely because they resist comparison. Autonomy allows for genuine self-authorship, because what makes the choice between two incommensurable goods right is that one chooses it for oneself. As Joseph Raz puts their point, "since it follows that there is no reason to shun one of the alternatives in favor of the other, we are in a sense free to choose which course to follow". ${ }^{23}$

Yet, as Bustamante and Decat appreciate, inasmuch as two people might choose incommensurably valued goods that cannot be mutually realized in practice, they might find themselves in moral combat - that is, in a circumstance in which one cannot succeed in realizing an autonomously chosen good unless the other fails to do the same. To take their example, Mary might choose to pursue knowledge of the natural world, while Jane might choose to pursue a life of religious devotion. When Mary's chosen path motivates research on human embryos she may collide with Jane's chosen path to protect Godly creations that have been invested with life potential. ${ }^{24}$ "Is this

22 Thomas Bustamante and Thiago Lopes Decat, "Incommensurability, Social Practices and Moral Dilemmas: A Rejoinder to Heidi Hurd's Anti-Perspectivalism", this volume, pp. 125-146.

23 Joseph Raz, The Morality of Freedom (Oxford 1986) 325 and 326.

24 Bustamante and Decat, p. 141. 
not real moral combat?", they ask. "Should not we accept that, under certain cases, morality commits us to incommensurable yet valuable pursuits that might turn us into moral competitors? If the answer is "yes", ...then Hurd's denial of moral combat is but a misrepresentation of the reality of our moral arguments". ${ }^{25}$

I take there to be three rejoinders that are independently sufficient to take the wind out of this challenge, even as I admire the forceful defense of it that Bustamante and Decat provide. First, Bustamante and Decat do not provide any defense of the claim that there are, in fact, incommensurable goods; and in my view there is no defense to give. Citing proponents of the incommensurability thesis who themselves provide extensive characterizations of the phenomenon without, in fact, advancing arguments for why we should believe it exists, ${ }^{26}$ Bustamante and Decat content themselves with anecdotal examples of purported incommensurability, like the one about Mary and Jane, rather than offering persuasive arguments to think that our best moral theory would bar us from making reasoned choices between things of value because those things cannot be compared. In my view, the claim that fundamental values are incommensurable is highly implausible. It is belied by daily practice and it is embarrassed by the fact that it permits moral dilemmas and invites moral combat.

After all, we regularly make reasoned choices between things of value. We take those choices to be hard precisely because we think of them as having right answers, and we take our task to be that of determining what those answers are. We are, of course, so epistemically handicapped when it comes to making long-range, life-altering decisions that trade on mutually incompatible values that we settle for identifying options that are "better" or "worse", rather than right or wrong. But we do not consider ourselves to be free to flip coins - which is precisely what we would be licensed to do if our choices were right, whatever we chose. Whether to go to college or join the military; whether to become a nurse or an environmental activist; whether to pursue the life of a scholar or a dancer; whether

25 Bustamante and Decat, p. 141.

26 See, e. g., Raz, Morality of Freedom, 325-335. 
to fight wildfires or to study music; whether to stay close to home or allow career opportunities to take us far away from family; all of these choices may be ours alone to make because we have the most information about their ramifications, and because our preferences themselves provide agent-relative reasons to weight some options more heavily than others. But we agonize about such choices precisely because we take such options to have merits that are susceptible to discovery and reasoned comparison; we do not take our unreasoned preferences to be dispositive of what we ought to do because they alone make right our choices. Were these choices between goods of incommensurable value, there would be no reason for them to be hard choices, for we could have no fear of condemnation. No one could judge us poorly for "wasting our talents", or "being overly romantic", or "selling ourselves short", or "trying to play the hero", or "disappointing our parents", or "being short-sighted".

Bustamante and Decat consider the example in which Mary and Jane pursue lives of knowledge and religious faith, respectively, to vindicate the notion that there are incommensurable values that might, in practice, demand moral combat. But few will consider Mary's and Jane's choices immune from moral judgment - particularly because they concern matters of value to others, and not just to themselves. Mary seeks the good of those whose lives can be saved or made better by the knowledge gained from embryo research. Jane seeks the protection of embryos either for their own sakes or God's. Surely when people seek to speak for others, rather than themselves, they do not get to immunize their judgments by insisting that they possess a weight that cannot be assessed. In my view, this example is a particularly good example of a dispute that is not immune to reasoned resolution, precisely because their choices do not alone matter to the question of whether they have made the right choices. As such, it seems to me a particularly unlikely example of true moral combat, even as, of course, the epistemic constraints on each actor might make both think that their choice is on moral par with that of the other ${ }^{27}$

27 As I make clear in my book, there are lots of instances in which people may be epistemically justified in believing that their moral success requires another's moral failure. But the correspondence thesis is not an epistemic one; it is not a 
The second rejoinder that, in my view, ought to quell the notion that moral combat can be predicated on moral incommensurability follows from examining two possible interpretations of the nature of the "freedom" that Bustamante and Decat accord to actors who each choose to pursue a value incommensurable with that of the other. On the first interpretation, each has a true permission to act (or as Michael Moore and I call it, a "protected permission"), ${ }^{28}$ even if so doing will thwart the action of the other. On the second interpretation, both simply possess Hohfeldian liberties to pursue goods of incommensurable value. Inasmuch as the mutual exercise of liberties can be mutually incompatible, each can be foiled by the other without having any moral complaint.

Only the second interpretation can make sense of how two persons might be blameless in thwarting one another's actions, for the first interpretation rests on a fundamental confusion. To have a true (protected) permission to do an act is to be in a position in which (1) others have no right that one not do the act; and (2) others have a duty not to interfere with one's doing of the act. ${ }^{29}$ Put colloquially, to have a true (protected) permission is to have a right to do an act. Inasmuch as rights give rise to duties of noninterference on the part of others, then two actors cannot simultaneously be permitted to act in ways that confound the other's efforts. For this would mean that one could have a right to do what another has a right that one not do.

On the second interpretation, however, two actors, each in pursuit of values of incommensurable weight, may indeed find themselves in circumstances in which each blamelessly thwarts the actions of the other. This is because when one only has a Hohfeldian liberty to do an act, others have no right that one not do the act; but they may still have a right to interfere with one's act, and in such

thesis about the relationship between two actors' justified beliefs. Rather, it is a thesis about justified actions.

28 Moore and Hurd, Moral Combat: Disagreement in Action Not Belief, p. 24 [Draft p. 17, first paragraph in sec. B.4.].

29 Wesley Newcomb Hohfeld, Fundamental Legal Conceptions, ed. W.W. Cook (Yale University Press 1919) 36-39. 
a case, one has no right that they not interfere. Why does this not constitute a confession that moral combat is possible, at least if the incommensurability of values is plausible? The answer is because when only Hohfeldian liberties are at stake, actors are genuinely in a moral state of nature; they do no wrong, but they also do no right, in acting as they do, even at the expense of others. Their actions are amoral. It is therefore a matter of moral indifference if one thwarts another or is thwarted by another. Inasmuch as my arguments for the correspondence thesis are arguments about the conditions of moral action, it is neither troubling, nor surprising, that they are inapplicable to amoral actions.

Bustamante and Decat reply by insisting that if each is employing a Hohfeldian liberty to pursue a good possessed of value incommensurable to that of any other, then surely it is a mistake to describe their struggles as a matter of moral indifference. "The choice among incommensurable comprehensive goals is neither amoral nor normatively irrelevant. On the contrary, "the fact that goals are integrated with central aspects of our lives, that they represent what matters to us in life, makes them constitutive of our well-being". ${ }^{30}$

If incommensurable values exist, I am happy to concede that they are moral values ("That which we call a rose by any other name would smell as sweet"). ${ }^{31}$ But this does not make an actor's choice among them morally significant. Precisely because actors are "free" to choose - precisely because it follows from their incommensurability that no value is more weighty than any other, and thus that no choice is either better or worse than any other- morality is indifferent to the choice between them; that choice is itself amoral. And if that amoral choice, by virtue of being amoral, is protected only by a liberty, then while no one else has a right that the choice not be made, no one else has an obligation to respect that choice by refraining from interfering with its execution. Conflicts may abound; but they are not moral conflicts, and they are thus certainly not examples of moral combat. Moral combat arises when two actors each

30 Bustamante and Decat, p. 135.

31 William Shakespeare, "Romeo and Juliet" in The Norton Shakespeare, ed. Stephen Greenblatt (W.W. Norton \& Company Inc. 1997). 
have moral rights, or even categorical moral duties, to act in ways that will thwart one another. One cannot find moral combat in conflicts between actors at liberty to pursue incommensurable values, precisely because morality does not (cannot) speak to their choices, and therefore, does not (cannot) protect them with robust rights that would turn these actors into moral gladiators in circumstances in which the success of one came at the expense of the other.

This brings me to the third and final rejoinder to Bustamante's and Decat's important critique, which is that their critique effectively uses the concept of "incommensurable value" to achieve the same thing that relativists achieve with the notion of "relative value". The upshot of declaring values incommensurable is to make choices about them immune from moral criticism in the same way that a relativist makes choices immune from criticism by insisting that their rightness is a function of the actor believing them to be right. On Bustamante's and Decat's view, the incommensurability of their choices effectively makes two actors equally right in pursuing goals that are mutually incompatible. But then, in a manner that is structurally identical to the relativist's view, what is right for actor $A$ in circumstance $C$ may be wrong for actor B in precisely the same circumstance, for the only thing that makes actions right or wrong are actors' choices to perform them. Bustamante and Decat buy on the cheap what relativists purchase with far more expensive meta-ethics. But in my view, both get what they pay for: an implausible moral theory that perversely celebrates possibilities of moral conflict, moral combat, and even moral contradiction.

Now let me close by stepping away from the specifics of the engaging controversies generated by the extraordinarily thoughtful contributions to this volume. My responses to my valued colleagues barely scratch the surface of their complex, deeply penetrating analyses, and they would be right to think that I left without discussion many lines of inquiry that are worth considerable discussion. It is testament to their philosophical acuity and creativity that a complete response to each of their many insightful comments would require another book. I thank them for finding the anniversary of my work on moral combat a fitting occasion upon which to throw down 
vigorous challenges to take up where I left off twenty years ago. I am surely energized do so, if only to continue the lively and important conversations that have been initiated by this volume. But I will be more gratified, still, if the efforts of my thoughtful critics ignite interest and ambition in the next generation of scholars to take up the important questions that animate this collection.

\section{REFERENCES}

Bustamante Thomas and Thiago Lopes Decat, "Incommensurability, Social Practices and Moral Dilemmas: A Rejoinder to Heidi Hurd's Anti-Perspectivalism".

Hohfeld Wesley Newcomb, Fundamental Legal Conceptions, ed. W. W. Cook (Yale University Press 1919).

Hurd Heidi M., Moral Combat (Cambridge University Press 1999).

Hurd Heidi M., "Relativistic Jurisprudence: Skepticism Founded on Confusion" (1988) 61 Southern California Law Review.

Hurd Heidi M., "The Virtue of Consumer Bankruptcy" in R Brubaker, RM Lawless, CJ Tabb (eds.), A Debtor World: Interdisciplinary Perspectives on Debt (Oxford 2012) 317-44.

Hurd Heidi M. and Ralph Brubaker, The Virtue of Bankruptcy (Oxford forthcoming).

Lyons David, Forms and Limits of Utilitarianism (Oxford 1965). Alexander, Larry, "Pursuing the Good Indirectly" 95 (1985) Ethics.

Matos Saulo M.M. de, "A Wittgensteinian-Based Moral Realism: Deflating Hurd's Moral Combat Antimony".

Moore Michael S. and Heidi M. Hurd, "Moral Combat: Disagreement in Action, Not Belief".

Porto Macedo Jr. Ronaldo, “Is Bernard Williams' Distance Relativism Really Defeated by Heidi Hurd's Attack on Perspectivalism?". Rawls John, "Two Concepts of Rules" (1955) 64 The Philosophical Review. 
Raz Joseph, The Morality of Freedom (Oxford 1986).

Reeves Anthony R., "Do Judges Have an Obligation to Enforce the Law?: Moral Responsibility and Judicial-Reasoning" (2010) 29 Law and Philosophy.

Shakespeare William, "Romeo and Juliet" in The Norton Shakespeare, ed. Stephen Greenblatt (W.W. Norton \& Company Inc. 1997).

Souza Faggion Vinicius de, "Is the Judicial Role Just a Descriptive Social Fact?". 